\title{
Wind Characteristics of Three Meteorological Stations in China
}

\author{
Yang Yang, ${ }^{1}$ Yao Gang, ${ }^{1}$ Wang Rong, ${ }^{1}$ and Wang Hengyu ${ }^{2}$ \\ ${ }^{1}$ College of Civil Engineering, Chongqing University, Chongqing 400044, China \\ ${ }^{2}$ Huadian New Energy Development Co., Gansu 730000, China \\ Correspondence should be addressed to Yao Gang; yaocqu@vip.sina.com
}

Received 22 July 2015; Revised 6 October 2015; Accepted 7 October 2015

Academic Editor: Petko Petkov

Copyright (C) 2015 Yang Yang et al. This is an open access article distributed under the Creative Commons Attribution License, which permits unrestricted use, distribution, and reproduction in any medium, provided the original work is properly cited.

\begin{abstract}
With rapid economic development of China, demand for energy is growing rapidly. Many experts have begun to pay attention on exploiting wind energy. Wind characteristics of three meteorological stations in China were analyzed to find out if or not it is possible to build a wind farm in this paper. First of all, studies about the wind characteristics and potential wind energy were summarized. Then ways of collecting and manipulating wind data were introduced. Wind-generation potential was assessed by the method of Weibull distribution. Wind shear exponent, extreme wind speed in 50 years, and turbulence intensity were calculated. The wind characteristics were summarized and assessment of wind-generation potential was given. At last, the wind was simulated with autoregressive method by Matlab software.
\end{abstract}

\section{Introduction}

With rapid economic development of China, demand for energy is growing rapidly [1]. Electricity produced by consuming coal had taken up of $76 \%$ in the whole electricity. This led to the spring of 2013 when the fog hazy weather lasted for a long time in China.

China is one of the countries which have a large number of wind resources and make use of the wind resource in the early days. According to statistics [2], density of wind energy in China is about $100 \mathrm{~W} / \mathrm{m}^{2}$ on average, and the total wind energy amount is $3226 \mathrm{GW}$. The available development and utilization wind energy is about $253 \mathrm{GW}$ on land. The wind energy utilization has been growing at a fast pace around all over the world. But the utilization is held back by the shortage of wind data which are sufficient and credible. The wind speeds' distribution is not only significant to the wind farm designers but also to other power generators. Nowadays, vast quantities of information is offered to researchers by research of wind characteristic, investors, and wind farm planners that pay close attention to the renewable energy's evolution.

Gansu province which is the fifth on the potential wind energy in China has 237 million KW potential wind energy in theory [3]. Jiuquan region in Gansu is rich of wind energy, and its annual average wind density is above
$150 \mathrm{~W} / \mathrm{m}^{2}$. Nowadays, energy policy of China is committed to developing a kind of new energy which is abundant and free pollution with low cost. So considering the exploitation of wind energy resources in Jiuquan is required.

In the last five years, lots of researches had been done in China on potential wind energy and wind characteristics. Song et al. [4] investigated major measures of observation data and computational precision based on field measurement and analyses of a number of wind power facilities, in particular over complex terrain. Du et al. $[5,6]$ proposed an improved method which had the advantage of less uncertainty and less error in computing the wind speed of the representative year in wind farm and presented changes of the wind shear index basing on the measured data of three 70 meter-high wind towers of two consecutive years in Inner Mongolia. Peng et al. [7] studied the wind shear exponent for wind resource assessment and found that the wind shear exponent in different vertical layers calculated at different speed bins had the highest precision. Chen et al. [8] studied the wind characteristics in northwest and southeast of China by analyzing the observational data obtained from towers which were representative in the two areas. Fang et al. [9] analyzed the wind power in northeast of China. The method and model for wind energy resource investigation in cold area had been established in his study. Wen et al. [10] analyzed 


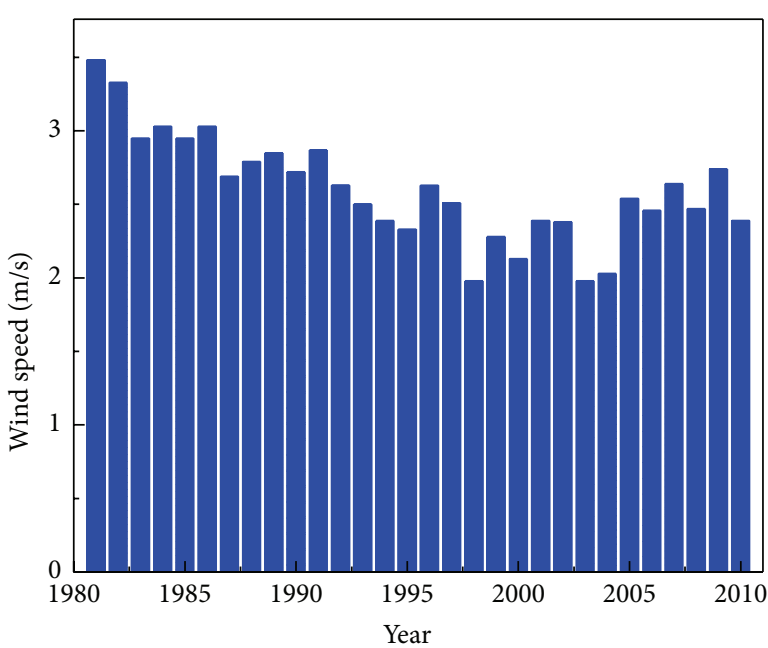

(a) Wind speed

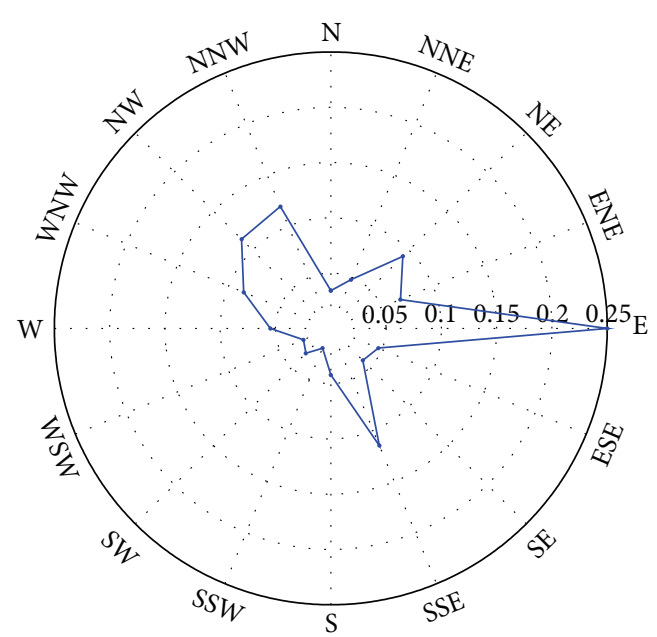

(b) Wind direction

FIGURE 1: Annual average wind speed and wind direction during 1981-2010 year in Guazhou meteorological station.

the reserves and distribution characteristics of wind speed and wind energy at $70 \mathrm{~m}$ height with statistical method, basing on observational data at $70 \mathrm{~m}$ height from 18 wind towers in Fujian coastal areas. Tong [11] put forward a new method of wind speed forecasting-wavelet decomposition autoregressive combined with wind speed change parting forecast method by bringing wind speed change characteristics types into wind speed prediction. Shang and Xie [12] developed logistic models according to the development characteristics of each province to predict development trend of wind power in 2013 2020, and predicting the main problems and measures should be taken by different provinces in the future. Bassyouni et al. [13] collected eleven years' wind data in Jeddah to determine the wind characteristics including the daily, monthly, and annual wind speed, wind probability density distribution, and shape $(k)$ and scale (c) parameters at $10 \mathrm{~m}$ height. Alam et al. [14] studied the variability of fluctuating nature of the wind both in time and spatial domain. By utilizing daily mean values of wind speed from different meteorological stations, dynamic nature of the wind at nine stations was analyzed in conjunction with wavelet transform and fast Fourier transform power spectrum techniques. Wu et al. [15] developed a prediction system to predict wind power with a method of combining statistical model and physical model. The inlet condition of the wind farm is forecasted by the autoregressive model in this system. The proposed prediction system was tested by the data from Wattle Point Wind Farm in Australia, and this system was effective for power output prediction of wind farm. Santamaría-Bonfil et al. [16] proposed a hybrid methodology based on Support Vector Regression for wind speed forecasting with autoregressive model, and results showed that forecasts made with this method were more accurate for medium short term wind power forecasting and wind speed forecasting than other models.

China has sufficient potential wind energy especially in the northwest region. But development of wind resource is under the expected standard until now. This paper aims to make sure of the wind's characteristics and simulate the wind with autoregressive method.

\section{Wind Speed Data Analysis}

2.1. Description of Wind Data Collection System. Guazhou meteorological station which belonged to national principal station was built in 1951 with a $1171 \mathrm{~m}$ altitude above sea level. The wind speed data from 1981 to 2010 was collected at Guazhou meteorological station. Measurement data was kept with EL and EL15-2/2A anemometer.

Wind farm was about $67 \mathrm{~km}$ away the northeast of Guazhou meteorological station, which had a similar geographic and geomorphic condition with Guazhou meteorological station. Therefore, quantitative data of Guazhou meteorological station could be used in analyzing the characteristics of wind.

The annual average wind speed and wind direction during 1981-2010 year in Guazhou was given in Figure 1. It can be calculated that $2.55 \mathrm{~m} / \mathrm{s}$ was the average speed in 30 years. Average wind speed kept stability and east wind direction was the prevailing wind direction. The month average wind speed during 1981-2010 year in Guazhou was given in Figure 2. The highest average speed was $3.4 \mathrm{~m} / \mathrm{s}$ in March and the smallest was $2.0 \mathrm{~m} / \mathrm{s}$ in October. It evidenced that wind in Guazhou kept stability in each month. Therefore it is possible to build a wind farm in this region.

More than fifty meteorological stations with $70 \mathrm{~m}$ height had been built in Jiuquan region to develop the wind recourse. There were three meteorological stations in the survey region, and hence all of them were selected to analyze the wind characteristics of the wind farm. The numbers of meteorological stations were 8158\#, 7411\#, and 8601\#. Table 1 gave the basic condition of the three meteorological stations. 
TABLE 1: Site specific information of meteorological stations considered in this paper.

\begin{tabular}{lcccccc}
\hline Number $H(\mathrm{~m})$ & Period & Coordinate & $\begin{array}{c}\text { Elevation } \\
(\mathrm{m})\end{array}$ & Wind tower configuration & $\begin{array}{c}\text { Instrument } \\
\text { device }\end{array}$ \\
\hline $8158 \#$ & 70 & $2008.09 .01-2011.04 .28$ & $\mathrm{~N}: 40^{\circ} 48^{\prime} 39^{\prime \prime}$ E: $96^{\circ} 31^{\prime} 20^{\prime \prime}$ & 1566 & Wind speed: 10, 30, 50, 70 direction: 10, 70 & NRG \\
\hline $7411 \#$ & 70 & $2008.09 .01-2011.04 .27$ & $\mathrm{~N}: 40^{\circ} 44^{\prime} 28^{\prime \prime}$ E: $96^{\circ} 31^{\prime} 18^{\prime \prime}$ & 1494 & Wind speed: 10, 30, 50, 70 direction: 10, 70 & NRG \\
\hline $8601 \#$ & 70 & $2008.08 .25-2011.04 .28$ & $\mathrm{~N}: 40^{\circ} 45^{\prime} 33^{\prime \prime}$ E: $96^{\circ} 24^{\prime} 46^{\prime \prime}$ & 1500 & Wind speed: 10, 30, 50, 70 direction: 10,70 & NRG \\
\hline
\end{tabular}

TABLE 2: Valid data's rate of three meteorological stations.

\begin{tabular}{lccccc}
\hline Time & $2008.9 .01-2011.4 .28$ & $2008.9 .01-2008.12 .31$ & $2009.1 .01-2009.12 .31$ & $2010.1 .01-2010.12 .31$ & $2011.1 .01-2011.4 .28$ \\
\hline $8158 \#$ & $93.64 \%$ & $95.16 \%$ & $95.83 \%$ & $89.76 \%$ & $97.31 \%$ \\
$7411 \#$ & $96.47 \%$ & $97.20 \%$ & $96.71 \%$ & $95.28 \%$ & $98.68 \%$ \\
$8601 \#$ & $89.32 \%$ & $95.33 \%$ & $80.09 \%$ & $95.59 \%$ & $96.74 \%$ \\
\hline
\end{tabular}

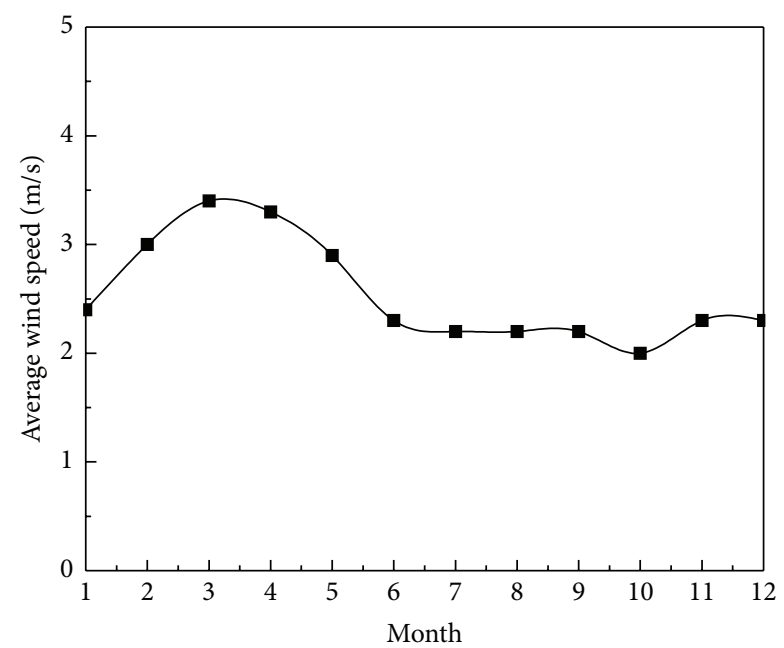

FIGURE 2: Month average wind speed during 1981-2010 year in Guazhou meteorological station.

2.2. Manipulation of Wind Data. In order to get the assessment which was most close to the actual wind power generation potential in the wind farm, the collected wind data were separately checked by all of wind data and the wind data which were measured in 2009 year. NRG anemoscopes were used in the meteorological stations, and sampling frequency of wind speed was $1 \mathrm{~Hz}$. Data of wind speed and wind direction was output each $10 \mathrm{~min}$. Sampling frequency of extreme wind speed was $2 \mathrm{~Hz}$. Collection of wind direction kept the same pace with the wind speed, and all of wind direction records were moment sampling values. The anemoscopes could store the wind data collected in three months completely, and the staff got the wind data every two months. According to [17], the wind data were checked with data integrity, data scope, data dependency, and trend of wind speed. The unreasonable and missing data were deleted. At last, all the unreasonable data were collected and the rationality of data was judged again. The valid data were picked out and returned to the original data set. Table 2 showed that the entire rate of valid data was beyond $80 \%$ during observation period.
In order to check the correlation between wind speed and wind direction, wind data collected from different meteorological stations were selected. Correlation between wind speed and wind direction was analyzed between $8601 \#$ and 8158\#, 8601\# and 7411\#, and 8158\# and 7411\# meteorological stations. Table 3 showed the related equation and correlation coefficient between 8601\# and 8158\#, 8601\# and $7411 \#$, and $8158 \#$ and $7411 \#$ at $70 \mathrm{~m}$ height in 2009 year. The wind data between 8601 \# and 7411\# was taken as an example, the total correlation coefficient was 0.859 , and the related equation was $Y=0.869 X+0.623$. The 8601 \# and 7411 \# mainly wind correlation coefficient was above 0.75 . The wind speed had a good correlation coefficient in three meteorological stations. It can be seen that wind power generation potential in the wind farm was almost the same.

From the checked results of wind data, the 8601\#, 8158\#, and 7411\# meteorological stations can meet the requirement of design with more than $95 \%$ effective data. The monthly average wind speed data in 2009 collected from three meteorological stations at different heights were compared in Figure 3. It showed that wind speed data in 2009 collected from three meteorological stations at the same height had a good agreement, and hence wind speed data in 2009 had a certain representation. From Figure 3, it also can be seen that the wind speed was concentrated mainly on $5 \mathrm{~m} / \mathrm{s}-9 \mathrm{~m} / \mathrm{s}$. Invalid wind speed under $3 \mathrm{~m} / \mathrm{s}$ was rare, and there was no destructive wind all over the year. With the small change of the wind speed, this wind farm can generate electricity through the whole year.

\section{Wind Characteristic Analysis}

3.1. Weibull Parameter of Wind Speed. In the studied areas, frequency distribution of wind speed is a principal element to evaluate potential wind power. Potential wind power in this wind farm must be determined by the Weibull distribution. The range of wind data is wide. As a consequence, keeping a few important parameters which could certify the behavior of wind speed data with a wide range is requisite. Using a distribution function is the easiest method for the procedure, and the most widely used function is Weibull function. 
TABLE 3: Correlation coefficient of three meteorological stations.

(a) Correlation coefficient of $8601 \#$ and $8158 \#$ meteorological stations at $70 \mathrm{~m}$ height

\begin{tabular}{lcc}
\hline \multicolumn{3}{c}{$\begin{array}{c}\text { The total correlation equation: } Y=0.884 X+0.556 \\
\text { Correlation coefficient: }\end{array}$} \\
Quadrant & Correlation equation & Correlation coefficient \\
\hline N & $Y=0.605 X+1.824$ & 0.627 \\
NNE & $Y=0.776 X+0.414$ & 0.879 \\
NE & $Y=0.906 X+0.132$ & 0.8 \\
ENE & $Y=0.956 X+0.099$ & 0.843 \\
E & $Y=0.862 X+1.130$ & 0.824 \\
ESE & $Y=0.797 X+1.485$ & 0.746 \\
SE & $Y=0.787 X+1.096$ & 0.8 \\
SSE & $Y=0.605 X+1.370$ & 0.664 \\
S & $Y=0.532 X+1.369$ & 0.603 \\
SSW & $Y=0.481 X+1.371$ & 0.553 \\
SW & $Y=0.714 X+0.907$ & 0.676 \\
WSW & $Y=0.869 X+0.512$ & 0.829 \\
W & $Y=0.893 X+0.365$ & 0.871 \\
WNW & $Y=0.860 X+0.328$ & 0.855 \\
NW & $Y=0.834 X+0.497$ & 0.846 \\
NNW & $Y=0.840 X+1.090$ & 0.772
\end{tabular}

(b) Correlation coefficient of $8601 \#$ and 7411\# meteorological stations at $70 \mathrm{~m}$ height

\begin{tabular}{lcc}
\hline & $\begin{array}{r}\text { The total correlation equation: } Y=0.869 X+0.623 \\
\text { Correlation coefficient: } 0.859\end{array}$ \\
Quadrant & Correlation equation & Correlation coefficient \\
\hline N & $Y=0.607 X+2.020$ & 0.635 \\
NNE & $Y=0.796 X+0.487$ & 0.882 \\
NE & $Y=0.820 X+0.731$ & 0.75 \\
ENE & $Y=0.917 X+0.173$ & 0.819 \\
E & $Y=0.876 X+0.623$ & 0.798 \\
ESE & $Y=0.785 X+0.967$ & 0.766 \\
SE & $Y=0.840 X+0.623$ & 0.849 \\
SSE & $Y=0.717 X+0.946$ & 0.769 \\
S & $Y=0.665 X+1.041$ & 0.721 \\
SSW & $Y=0.576 X+1.219$ & 0.626 \\
SW & $Y=0.800 X+0.719$ & 0.798 \\
WSW & $Y=0.902 X+0.441$ & 0.885 \\
W & $Y=0.918 X+0.429$ & 0.898 \\
WNW & $Y=0.910 X+0.561$ & 0.876 \\
NW & $Y=0.860 X+0.902$ & 0.846 \\
NNW & $Y=0.807 X+1.597$ & 0.772
\end{tabular}

(c) Correlation coefficient of 8158\# and 7411\# meteorological stations at $70 \mathrm{~m}$ height

\begin{tabular}{lcc} 
& \multicolumn{2}{c}{$\begin{array}{c}\text { The total correlation equation: } Y=0.918 X+0.682 \\
\text { Correlation coefficient: } 0.932\end{array}$} \\
Quadrant & Correlation equation & Correlation coefficient \\
\hline $\mathrm{N}$ & $Y=0.786 X+0.671$ & 0.802 \\
$\mathrm{NNE}$ & $Y=0.959 X+0.114$ & 0.964 \\
$\mathrm{NE}$ & $Y=1.000 X+0.207$ & 0.933 \\
$\mathrm{ENE}$ & $Y=0.974 X+0.575$ & 0.949 \\
$\mathrm{E}$ & $Y=0.907 X+1.112$ & 0.943 \\
ESE & $Y=0.958 X+1.081$ & 0.926
\end{tabular}

(c) Continued.

\begin{tabular}{lcc}
\hline & $\begin{array}{r}\text { The total correlation equation: } Y=0.918 X+0.682 \\
\text { Correlation coefficient: } 0.932\end{array}$ \\
Quadrant & Correlation equation & Correlation coefficient \\
\hline SE & $Y=0.903 X+0.800$ & 0.875 \\
SSE & $Y=0.743 X+0.983$ & 0.735 \\
S & $Y=0.669 X+0.878$ & 0.695 \\
SSW & $Y=0.573 X+1.129$ & 0.642 \\
SW & $Y=0.746 X+0.687$ & 0.737 \\
WSW & $Y=0.886 X+0.514$ & 0.858 \\
W & $Y=0.905 X+0.482$ & 0.909 \\
WNW & $Y=0.841 X+0.658$ & 0.873 \\
NW & $Y=0.878 X+0.377$ & 0.898 \\
NNW & $Y=0.921 X+0.261$ & 0.875 \\
\hline
\end{tabular}

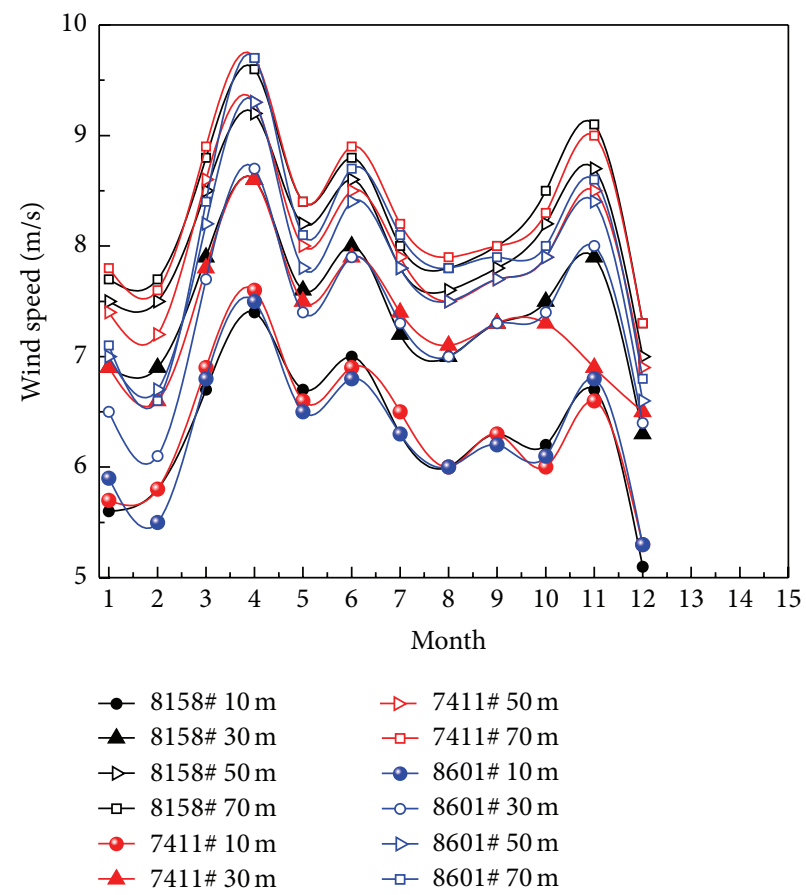

FIGURE 3: Wind speed of three meteorological stations at different heights in 2009 year.

The two-parameter distribution Weibull function could be showed in what follows:

$$
f(V)=\frac{k}{c}\left(\frac{V}{c}\right)^{k-1} \times e^{-(V / c)^{k}},
$$

where $k$ is a dimensionless parameter of Weibull shape, $c$ is a Weibull scale parameter, and $V$ is the wind speed, $\mathrm{m} / \mathrm{s}$. For the sake of assessing $k$ and $c$, different kinds of ways have been come up with. Wind power can be assessed with the following:

$$
W=\frac{1}{2} \rho v^{3}
$$


TABLE 4: The Weibull parameters at different heights.

\begin{tabular}{lccccccccc}
\hline Number & Parameter & $10 \mathrm{~m}$ & $30 \mathrm{~m}$ & $50 \mathrm{~m}$ & $65 \mathrm{~m}$ & $70 \mathrm{~m}$ & $75 \mathrm{~m}$ & $80 \mathrm{~m}$ & $90 \mathrm{~m}$ \\
\hline \multirow{2}{*}{$8158 \#$} & $c$ & 6.4 & 7.9 & 8.6 & 8.8 & 8.8 & 8.9 & 9.0 & 9.1 \\
& $k$ & 1.85 & 2.2 & 2.24 & 2.16 & 2.16 & 2.16 & 2.16 & 2.16 \\
\hline \multirow{2}{*}{$7411 \#$} & $c$ & 6.6 & 7.8 & 8.5 & 8.8 & 8.9 & 9.0 & 9.1 & 9.2 \\
& $k$ & 1.92 & 2.14 & 2.21 & 2.15 & 2.15 & 2.16 & 2.16 & 2.16 \\
\hline \multirow{2}{*}{$8601 \#$} & $c$ & 6.5 & 7.8 & 8.3 & 8.4 & 8.5 & 8.5 & 8.6 & 8.8 \\
& $k$ & 1.86 & 2.16 & 2.15 & 2.05 & 2.05 & 2.05 & 2.05 & 2.06 \\
\hline
\end{tabular}

where $W$ is the wind power density, $\rho$ is average air density, and $v$ is the average speed at $10 \mathrm{~m}$ height. Air density is calculated by

$$
\rho=\frac{1.276}{1+0.00366 t} \times \frac{p-0.378 e}{1000},
$$

where $t$ is temperature on average, $p$ is the air pressure on average, and $e$ is the average vapor pressure. The air density in the wind farm is $1.045 \mathrm{~kg} / \mathrm{m}^{3}$.

The Weibull parameters were determined by using the software WASP10.0 in this paper. Table 4 showed the results of two Weibull parameters $k$ and $c$ at different height and different meteorological stations. Weibull parameters $k$ and $c$ ranged from 1.85 to $2.16,6.4$ to 9.1 separately. Both of $k$ and $c$ increased with the height under $50 \mathrm{~m}$ and kept nearly steady above the $50 \mathrm{~m}$ height. The wind speed frequency distribution Weibull fit curves at different height were described in order to check the calculate results. Table 5 showed density of wind power and wind speed at different height. Wind speeds in three meteorological stations were almost the same and had an error of no more than $4.6 \%$ at the same height. Average power density of wind ranged from $374 \mathrm{~W} / \mathrm{m}^{2}$ to $503 \mathrm{~W} / \mathrm{m}^{2}$ when the height of meteorological station changed from $50 \mathrm{~m}$ to $90 \mathrm{~m}$ height and had an error of no more than $9.9 \%$ at the same height. According to the standard [18], the grade of this wind farm was beyond three, and wind energy resources were abundant and steady.

3.2. Calculation of Wind Shear Exponent. Wind shear exponent is a key factor on wind turbine safety in wind resource assessment. Wind shear exponent in different vertical layers calculated in different speed bins has the highest precision in all methods, while the wind shear exponent calculated by the exponent law has the characteristic of high credibility and high stability. Thus exponent law was used in this paper. Wind shear exponent can be calculated by

$$
a=\frac{\lg \left(v_{2} / v_{1}\right)}{\lg \left(z_{2} / z_{1}\right)},
$$

where $v_{2}$ is wind speed at $z_{2}$ height and $\mathrm{m} / \mathrm{s}, v_{1}$ is speed at $z_{1}$ height, $\mathrm{m} / \mathrm{s}$.

Table 6 showed the results of wind shear at different heights. When the height is above the $70 \mathrm{~m}$ height, the wind shear exponent is constant and independent of height. Therefore the wind shear exponent was assigned a value of 0.13 when the height was above $70 \mathrm{~m}$ height.
TABLE 5: Power density of wind and wind speed of three meteorological stations.

\begin{tabular}{lcccccc}
\hline Number & \multicolumn{2}{c}{$\begin{array}{c}\text { Average wind speed } \\
(\mathrm{m} / \mathrm{s})\end{array}$} & \multicolumn{3}{c}{$\begin{array}{c}\text { Average power density of } \\
\text { wind }\left(\mathrm{W} / \mathrm{m}^{2}\right)\end{array}$} \\
& $50 \mathrm{~m}$ & $75 \mathrm{~m}$ & $90 \mathrm{~m}$ & $50 \mathrm{~m}$ & $75 \mathrm{~m}$ & $90 \mathrm{~m}$ \\
\hline $8158 \#$ & 7.60 & 7.9 & 8.08 & 396 & 453 & 487 \\
$7411 \#$ & 7.55 & 7.98 & 8.16 & 389 & 465 & 503 \\
$8601 \#$ & 7.38 & 7.61 & 7.79 & 374 & 422 & 453 \\
\hline
\end{tabular}

3.3. Extreme Wind Speed in 50 Years. Wind speed and turbulence intensity determine the grade of wind turbine generator system. The wind farm can be divided into three grades by extreme wind speed in 50 years, associating with three grades of wind turbine generator system. Extreme wind speed in 50 years determines the security and rationality of the wind farm. Table 7 showed the grade of wind farm.

Type I extreme value distribution method shown in (5) was used to assess the extreme wind speed in 50 years:

$$
V_{50-\max }=u-\frac{1}{\omega} \ln \left[\ln \left(\frac{250}{249}\right)\right],
$$

where $u$ is distribution location parameter, $u=17.04$. $\omega$ is distribution scale parameter, and $\omega=0.4892$.

Air density in this wind farm is $1.045 \mathrm{~kg} / \mathrm{m}^{3}$. Considering the change of air density, the extreme wind speed in 50 years should be modified with the condition of standard air density. Figure 4 showed the extreme wind speed in 50 years should be modified with the condition of standard air density.

3.4. Turbulence Intensity at Different Heights. Turbulence intensity function at the speed of $15 \mathrm{~m} / \mathrm{s}$ could be calculated from

$$
I_{T}=\frac{\delta}{V},
$$

where $V$ is the average speed between $14.5 \mathrm{~m} / \mathrm{s}$ and $15.5 \mathrm{~m} / \mathrm{s}$; $\sigma$ is corresponding wind speed standard deviation. Table 8 showed the turbulence intensity at different heights. Turbulence intensity was decreased with the increasing of height. Range of turbulence intensity variation is 0.108 to 0.059 . The $C$ standard wind farm turbulence intensity is 0.12 , so the turbulence intensity in this wind farm can meet the requirement [18]. 
TABLE 6: Results of wind shear at different heights.

\begin{tabular}{lcccccccccccc}
\hline Number & \multicolumn{9}{c}{$8158 \#$} & \multicolumn{1}{c}{$7411 \#$} & \multicolumn{3}{c}{$8601 \#$} \\
\hline$H(\mathrm{~m})$ & 10 & 30 & 50 & 70 & 10 & 30 & 50 & 70 & 10 & 30 & 50 & 70 \\
$\alpha$ & 0.146 & 0.147 & 0.132 & 0.131 & 0.138 & 0.139 & 0.139 & 0.130 & 0.142 & 0.142 & 0.135 & 0.129 \\
\hline
\end{tabular}

TABLE 7: Security grade of the wind farm.

\begin{tabular}{lccc}
\hline IEC grade & I & II & III \\
\hline Extreme wind speed in 50 years $(\mathrm{m} / \mathrm{s})$ & $<70$ & $<59.5$ & $<52.5$ \\
\hline
\end{tabular}

\section{Simulation of Wind Speed with Autoregressive Method}

Simulation of wind speed is particularly important for wind farms because of cost-related issues, dispatch planning, and energy markets operations. Typically, wind farm energy production is estimated using a fixed weighted measure of the wind farm's nominal power and forecasts from historical atmospheric data. Further, it has been stated that wind speed is one of most important variables related to wind power generation. Autoregressive model is commonly used for time series forecasting wind speed since they are able to capture persistence in a time series. Therefore, wind speed was simulated with autoregressive method in this paper. Principle of autoregressive model can be expressed from

$$
\begin{gathered}
\qquad(t)=\bar{v}(z)+v(t), \\
{\left[\begin{array}{c}
v^{1}(j \cdot t) \\
v^{2}(j \cdot t) \\
\vdots \\
v^{M}(j \cdot t)
\end{array}\right]=-\sum_{k=1}^{p} \psi_{k} \cdot\left[\begin{array}{c}
v^{1}[(j-k) \cdot t] \\
v^{2}[(j-k) \cdot t] \\
\vdots \\
v^{M}[(j-k) \cdot t]
\end{array}\right]} \\
+\left[\begin{array}{c}
N^{1}(j \cdot t) \\
N^{2}(j \cdot t) \\
\vdots \\
N^{M}(j \cdot t)
\end{array}\right], \\
(j \cdot t=0,1,2,3, \ldots, T, k \leq j) \\
\bar{v}(z)=\bar{v}(10)\left(\frac{z}{10}\right)^{\alpha},
\end{gathered}
$$

where $V(t)$ is simulation wind, $\bar{v}(z)$ is average wind, $v(t)$ is turbulent wind, and $\psi_{k}$ is regression coefficient. $N(t)$ is a Gaussian function, $p$ is the order of autoregressive mode, $\alpha$ can be found in Table $6, z$ is the height of wind, and $\bar{v}(10)$ is the average wind at the height of $10 \mathrm{~m}$.

Simulation of wind speed with autoregressive method was realized by Matlab software. Time step was defined as 0.1, calculation step was defined as 1024, and operation order was 4. Wind in April 2009 at $70 \mathrm{~m}$ height was simulated according to davenport spectrum with autoregressive method. Figures 5 and 6 gave the turbulent and average wind in 400 seconds. From Figure 5, it can be seen that turbulent wind ranged from
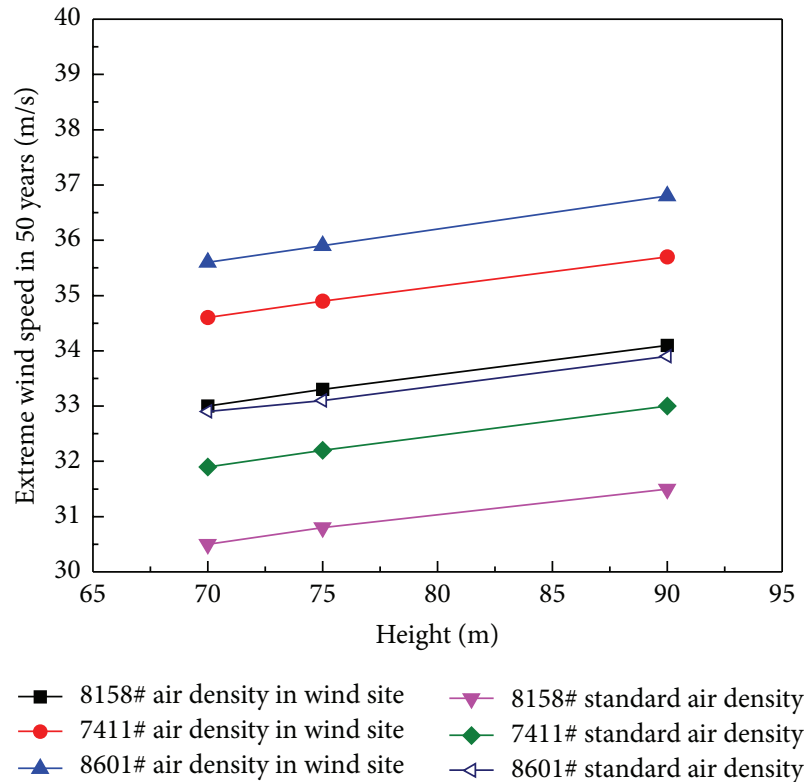

FIGURE 4: Comparison of wind speed between standard and actual air density.

TABLE 8: Turbulence intensity at different heights.

\begin{tabular}{lllll}
\hline No. & $70 \mathrm{~m}$ & $50 \mathrm{~m}$ & $30 \mathrm{~m}$ & $10 \mathrm{~m}$ \\
\hline $8158 \#$ & 0.059 & 0.073 & 0.093 & 0.109 \\
$7411 \#$ & 0.059 & 0.074 & 0.093 & 0.109 \\
$8601 \#$ & 0.062 & 0.076 & 0.089 & 0.108 \\
\hline
\end{tabular}

$-1 \mathrm{~m} / \mathrm{s}$ to $2 \mathrm{~m} / \mathrm{s}$ at $70 \mathrm{~m}$ height, and it fluctuated around $0 \mathrm{~m} / \mathrm{s}$. From Figure 6, it can be seen that average wind ranged from $6.5 \mathrm{~m} / \mathrm{s}$ to $9.5 \mathrm{~m} / \mathrm{s}$ at $70 \mathrm{~m}$ height, and it fluctuated around $7.4 \mathrm{~m} / \mathrm{s}$ which kept a good agreement with the measured wind speed data.

Simulated power spectrum was compared with the standard one in Figure 7, the simulated power spectrum agreed well with the standard power spectrum. With the data collected, turbulent wind and average wind at different heights can be simulated accurately with autoregressive method.

\section{Conclusions}

(1) East wind is the prevailing wind direction in this wind farm. The wind speed is strong in winter and spring. By analyzing the rate of valid data and comprising wind speed data between meteorological stations, wind data collected in 2009 were used to assess windgeneration potential. The wind frequency mainly concentrated on $5 \mathrm{~m} / \mathrm{s}-9 \mathrm{~m} / \mathrm{s}$. Invalid wind speed under 


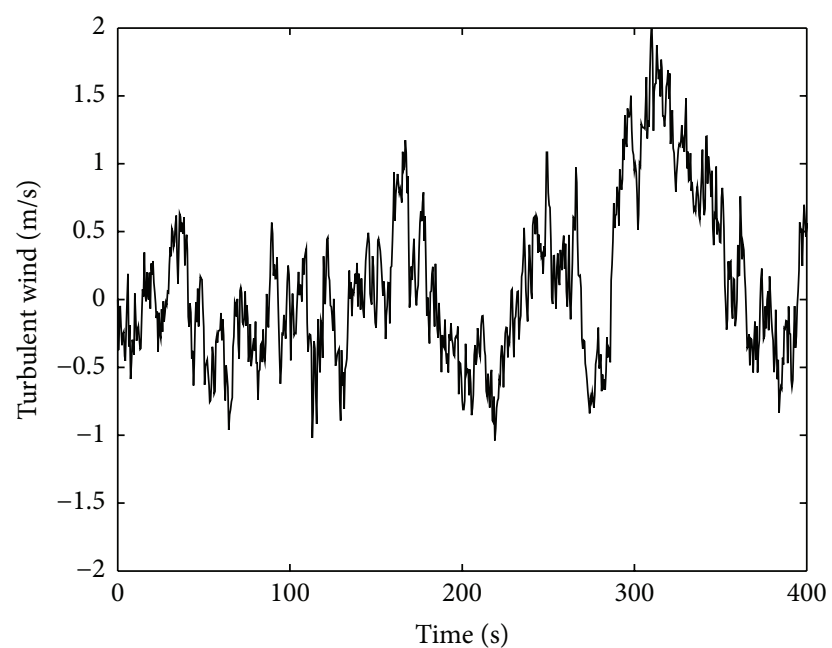

FIGURE 5: Turbulent wind in 400 seconds.

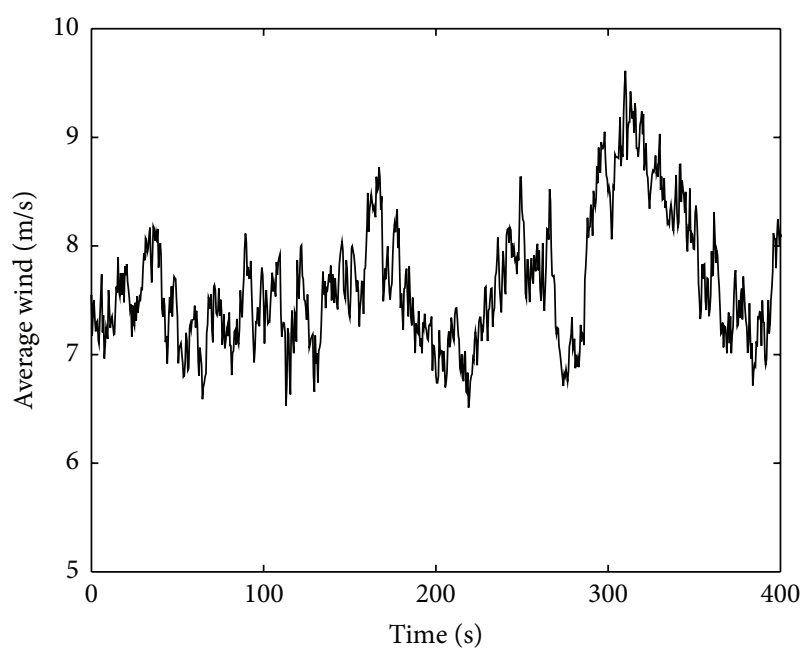

Figure 6: Average wind in 400 seconds.

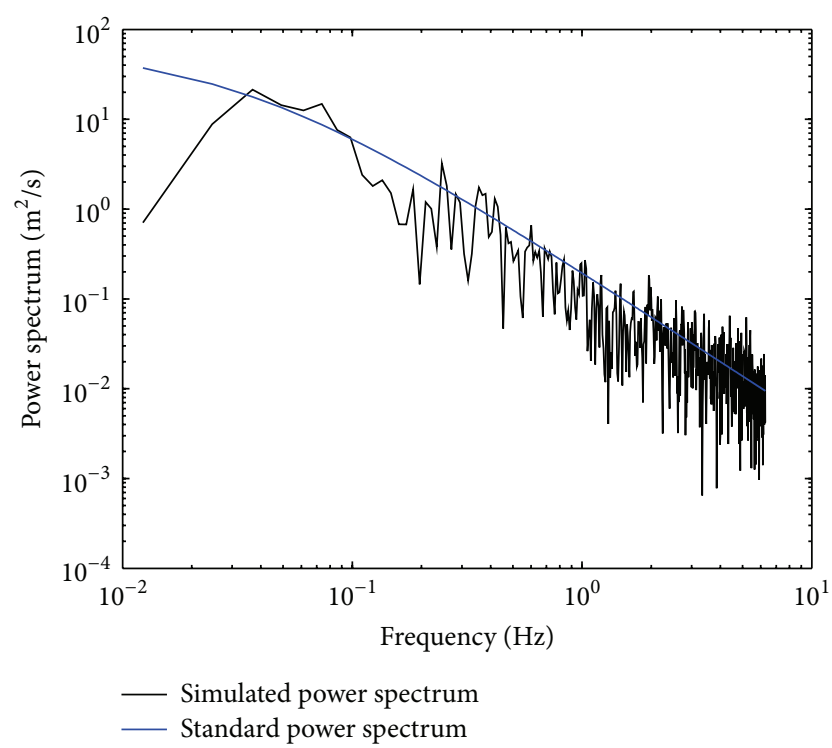

FIgURE 7: Simulated and standard power spectrum.
$3 \mathrm{~m} / \mathrm{s}$ was rare, and there was no destructive wind. With the small change of the wind speed, this wind farm can generate electricity through the whole year.

(2) Average wind power density at different heights was calculated. Average wind speed at $50 \mathrm{~m}$ height was $7.51 \mathrm{~m} / \mathrm{s}$ and the density of wind power on average was $387 \mathrm{~W} / \mathrm{m}^{2}$. The grade of wind farm was beyond three.

(3) Under the condition of standard air density the maximum wind speed in 50 years is $36.4 \mathrm{~m} / \mathrm{s}$ and $37.3 \mathrm{~m} / \mathrm{s}$ at the height of $75 \mathrm{~m}$ and $90 \mathrm{~m}$. Both of them are less than $37.5 \mathrm{~m} / \mathrm{s}$ which is the reference wind speed in third grade of wind farm. And hence it is possible to build a wind farm of third grade in this region.

(4) Range of turbulence intensity variation is 0.108 to 0.059 . The $C$ standard wind farm turbulence intensity is 0.12 , so the turbulence intensity in this wind farm can meet the requirement.

(5) With data collected and davenport spectrum, both wind speed at different heights and wind speed in this wind farm can be simulated accurately with autoregressive method.

\section{Conflict of Interests}

The authors declare that there is no conflict of interests regarding the publication of this paper.

\section{Acknowledgments}

This work was financially supported by science and technology project of Chongqing Municipal Construction Commission (20130844) and National Science Foundation of China (51578098).

\section{References}

[1] X. X. Wu, "Review of the energy work in 2013 and prediction of the energy work in 2014," Macroeconomic Management, vol. 19, no. 3, pp. 4-10, 2014.

[2] F. Wu and C. Fang, "Wind power resource appraisal and development stage regional division of China," Journal of Natural Products, vol. 24, no. 8, pp. 1413-1423, 2014.

[3] L. Shang and B. Xie, "Research on development trend of wind power in selected provinces of China," Renewable Energy, vol. 32, no. 2, pp. 191-196, 2014.

[4] L. L. Song, H. H. Huang, and S. Zhi, "Precision control in measurement and calculation of wind energy resource over wind power facilities," Meteorological Monthly, vol. 35, no. 3, pp. 73-81, 2009.

[5] Y. J. Du and C. Q. Feng, "Analysis on different computing method of wind speed of the representative year in wind farm," Renewable Energy Resources, vol. 28, no. 1, pp. 105-109, 2010.

[6] Y. J. Du and C. Q. Feng, "Application of wind shear index in the assessment of wind resources of wind farm," Power System and Clean Energy, vol. 26, no. 5, pp. 62-67, 2010. 
[7] H. W. Peng, C. Q. Feng, and Z. G. Bao, "Study on the wind shear exponent for wind resource assessment," Renewable Energy Resources, vol. 28, no. 1, pp. 21-25, 2010.

[8] X. Chen, L. L. Song, and H. H. Huang, "Study on characteristics of wind energy resources in two tipical areas in China," Acta Energiae Solaris Sinica, vol. 32, no. 3, pp. 331-338, 2011.

[9] F. Fang, L. Yan, and Q. Y. Li, "Wind energy investigation and feasibility analysis of wind power in cold areas of China," Journal of Northeast Agricultural University, vol. 42, no. 8, pp. 66-76, 2011.

[10] M. Z. Wen, B. Wu, and X. F. Lin, "Distribution characteristics and assessment of wind energy resources at $70 \mathrm{~m}$ height over Fujian coastal areas," Resources Science, vol. 33, no. 7, pp. 13461352, 2011.

[11] J. L. Tong, Research on change of wind speed and predicion of wind power in hexi corridor [Ph.D. thesis], Department of Applied Meteorology, Lanzhou University, Lanzhou, China, 2012.

[12] L. F. Shang and B. C. Xie, "Research on development trend of wind power in selected provinces of China," Renewable Energy, vol. 32, no. 2, pp. 191-196, 2014.

[13] M. Bassyouni, S. Gutub, U. Javaid et al., "Assessment and analysis of wind power resource using weibull parameters," Energy, Exploration \& Exploitation, vol. 33, no. 1, pp. 105-122, 2015.

[14] M. M. Alam, S. Rehman, L. M. Al-Hadhrami, and J. P. Meyer, "Extraction of the inherent nature of wind speed using wavelets and FFT," Energy for Sustainable Development, vol. 22, no. 1, pp. 34-47, 2014.

[15] B. H. Wu, M. X. Song, K. Chen et al., "Wind power prediction system for wind farm based on auto regressive statistical model and physical model," Journal of Renewable and Sustainable Energy, vol. 6, no. 1, Article ID 0131011, 13 pages, 2014.

[16] G. Santamaría-Bonfil, A. Reyes-Ballesteros, and C. Gershenson, "Wind speed forecasting for wind farms: a method based on support vector regression," Renewable Energy, vol. 85, pp. 790809, 2016.

[17] GB/T18710-2002, Methodology of wind energy resource assessment for wind farm.

[18] IEC6400-1-2005, International electro technical commission wind turbines. 

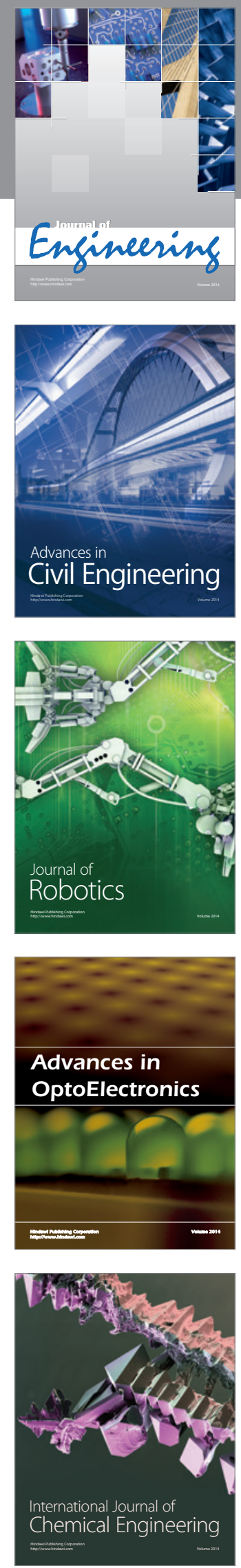

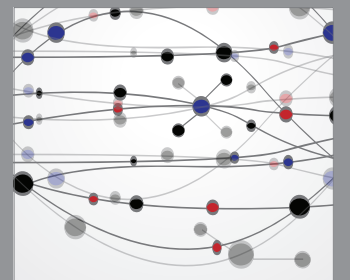

The Scientific World Journal
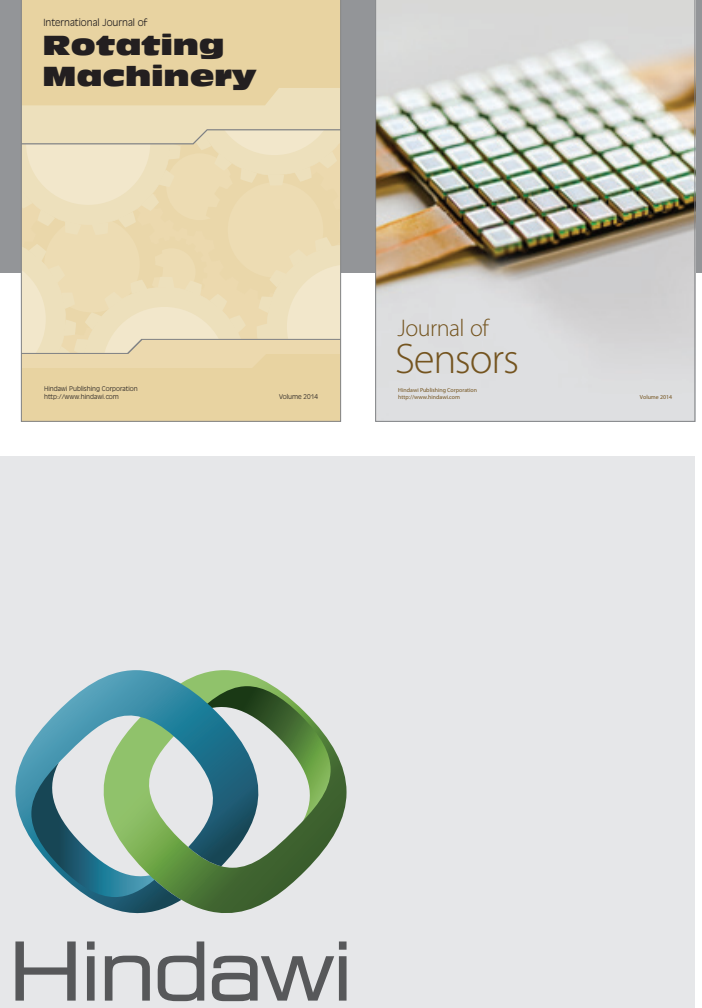

Submit your manuscripts at http://www.hindawi.com
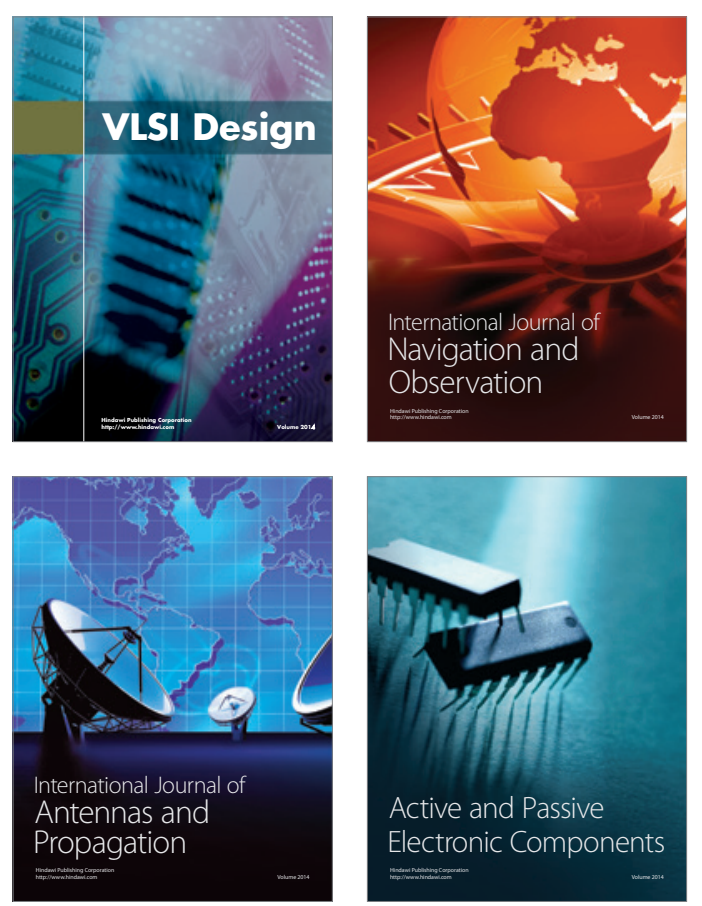
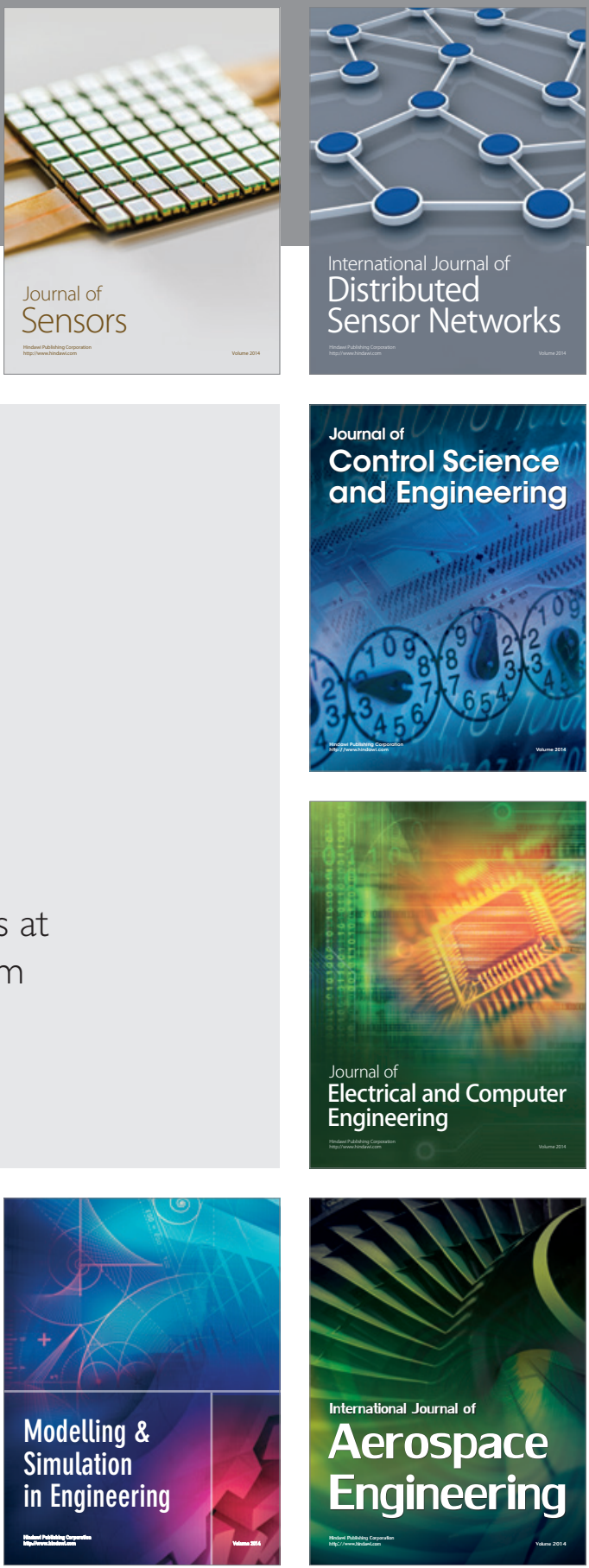

Journal of

Control Science

and Engineering
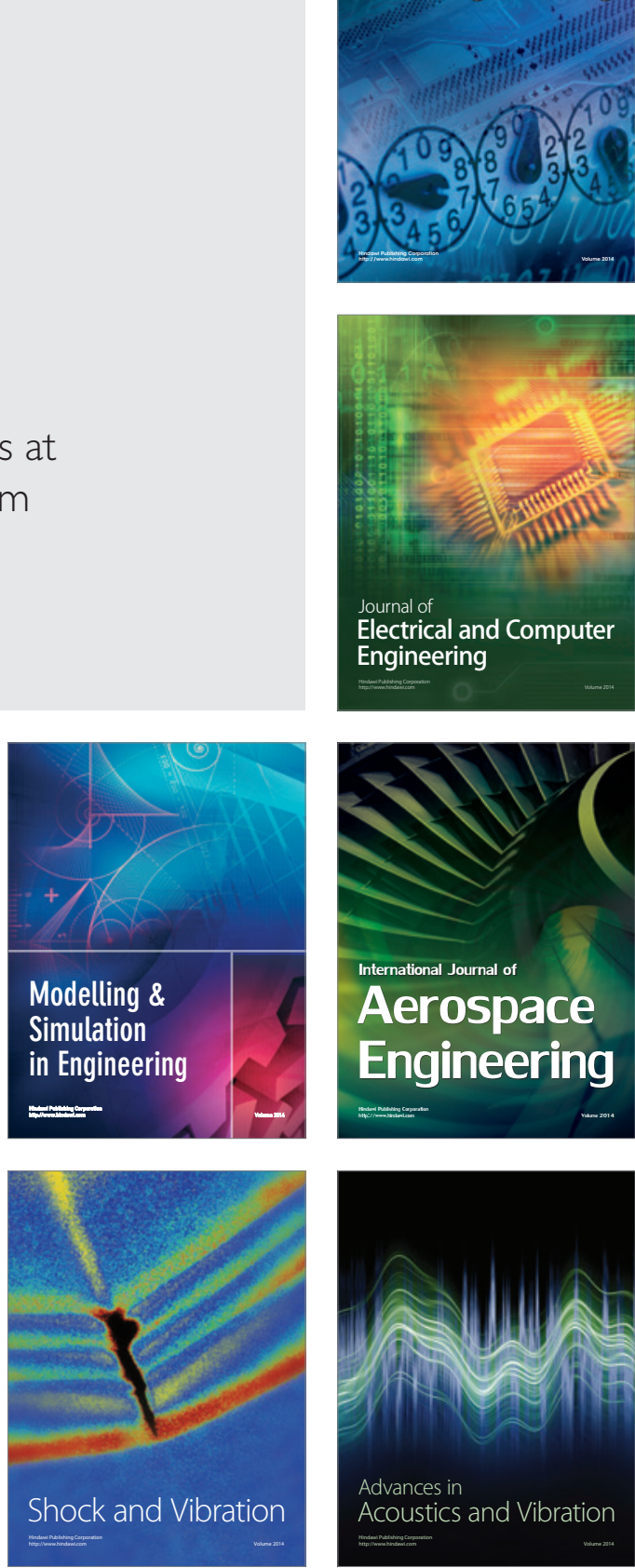